\title{
Microneedling and Oral Replacement of Collagen as Strategies for Skin Rejuvenation
}

\section{Érika Santos Freire ${ }^{1,2}$, Maria Cristina Vieira de Andrade ${ }^{1,2}$, Mônica de Albuquerque Costa ${ }^{1,2}$ Hudson Caetano Polonini ${ }^{3}$, Márcio Roberto ${ }^{4}$, Nádia Rezende Barbosa Raposo ${ }^{1}$}

${ }^{1}$ Núcleo de Pesquisa e Inovação em Ciências da Saúde (NUPICS), Faculdade de Farmácia, Universidade Federal de Juiz de Fora, Rua José Lourenço Kelmer, s/n, 36036-330, Juiz de Fora, MG, Brazil.

${ }^{2}$ Serviço de Dermatologia do Hospital Universitário da Universidade Federal de Juiz de Fora, Av. Eugênio do Nascimento, s/n, Dom Bosco, 36038-330, Juiz de Fora, MG, Brazil.

${ }^{3}$ Faculdade de Ciências Médicas e da Saúde de Juiz de Fora (Suprema), Alameda Salvaterra, no 200, Bairro Salvaterra, 36.033-003, Juiz de Fora, MG, Brazil.

${ }^{4}$ Embrapa Gado de Leite, Rua Eugênio do Nascimento, 610, Dom Bosco, 36038-330, Juiz de Fora, MG, Brazil. nadiacritt@gmail.com

*Corresponding Author: Érika Santos Freire, Rua José Lourenço Kelmer, s/n - São Pedro, Juiz de Fora - MG, 36036900, Brazil.

\section{Abstract}

Background: Skin aging is caused by a combination of intrinsic and extrinsic factors. The main clinical manifestations of photoaging are: presence of wrinkles, dilated pores, xerosis, roughness and sagging. The existing therapeutic options for photoaging treatment vary from topical agents to medical procedures. Microneedling consists of a physical stimulation performed through micropunctures in the skin, capable of inducing inflammatory response, and that results in the production of new collagen. Oral supplementation of hydrolyzed collagen to improve skin conditions has been studied.

Aims: To evaluate the microneedling technique associated with the oral supplementation of hydrolyzed collagen as skin rejuvenation strategies.

Methods: 30 volunteers were divided into 2 groups: group one (received two microneedling sessions associated with oral replacement of collagen for 6 months) and group 2 (received two microneedling sessions). Multispectral analysis of skin through Visia ${ }^{\circledR}$ equipment at 0, 30, 60 and 180 days and application of a selfperception questionnaire at 30 and 180 days were used as the evaluation method.

Results: Group 1 showed superior improvement of wrinkles in relation to group $2(p=0.032)$ and also of texture, without significance. The self-perception of significant improvement was high in both groups, but higher in group one.

Conclusion: The microneedling associated with oral collagen replacement can be considered an effective strategy in the treatment of cutaneous aging.

Keywords: Collagen; Rejuvenation; Skin Aging; Microneedling.

\section{INTRODUCTION}

Skin aging is known to be caused by a combination of intrinsic and extrinsic factors; in the later, excessive and chronic sun exposure to ultraviolet radiation is one of the main factors responsible for skin damage[1].
The main clinical manifestations characteristic of photoaging are changes in skin texture (wrinkles, dilated pores, cutaneous xerosis, roughness), changes in pigmentation, flaccidity and laxity, colloid cyst, comedonial actinic plaque, solar purple, skin fragility and skin tumours among others [2]. 
Currently a wide range of therapeutic options are available to treat photoaging: among the main agents are topical agents derived from retinoic and hydroxy acids, chemical peels, laser, dermabrasion and microneedling $[3,4]$.

The microneedle technique, also known as percutaneous collagen induction, is a recent treatment to combat the signs of skin aging [5]. Its principle consists of the physical stimulation performed through micropunctures on the surface of the skin, capable of inducing inflammatory response and stimulating the release of transforming growth factors $(\alpha-$ and $\beta$-TGF), connective tissue growth factor, connective tissue activation protein and fibroblast growth factor, without causing injury to the epidermis. In addition, micropunctures stimulate vascular neoformation in the dermis[6]. The entire process of cell signalling results in the production of extracellular matrix proteins, monocytes, keratinocytes and fibroblasts. The final product, then, is the formation of a new collagen, structured in an organised way, resulting in the improvement in the appearance of the skin $[5,7,8]$. The new collagen (type III) is progressively transformed into collagen type I, for a period of close to one year. The clinical aspects improve significantly from the 3rd month. Improvement in the appearance of the skin begins to occur at 3-4 weeks [4].

Complications related to the procedure are minimal and include: erythema, edema and superficial bleeding, depending on the length of the needle used; all resolved within a few hours to a maximum of 4872 hours. This fact makes the microneedle a welltolerated procedure, which causes a small withdrawal from work activities when compared with others such as dermabrasion and fractional laser carbon dioxide, which present greater potential for complications such as secondary infections, hyper or post-inflammatory hypopigmentation and scarring $[9,10]$.

Oral supplementation of hydrolysed collagen aimed at improving various skin conditions has been studied for some decades [11]. Recently, it has been found that the prolyl-hydroxyproline and glycine-hydroxyproline peptides are stable in peripheral blood and thus able to reach the cutaneous tissue [12]. A study in an animal model suggests that the ingestion of hydrolysed collagen peptides induces an increase in fibroblast density and, consequently, increases the production of dermal collagen fibrils [13]. In a double-blind randomised study, the improvement of wrinkle elasticity was demonstrated after oral collagen supplementation [14]. Improved skin hydration by reducing transepidermal water loss has also been observed, as well as improved the general appearance of the skin [15]. However, clinical studies are still few to demonstrate the effectiveness of such supplementation, especially when associated with microagglutination.

We proposed to evaluate the results of combined strategy (microneedling followed by collagen supplementation) with the purpose of skin rejuvenation.

\section{METHODS}

This was an open, monocentric, experimental study of 30 self-declared healthy male and female volunteers aged 45-65 years, levels II-III of ageing on the Glogau scale, with no phototype selection, who underwent two sessions of microneedling (30-days interval between them). The volunteers were divided for the convenience of the researcher, aiming to match smokers and non-smokers alike in both groups of 15 subjects: (i) supplemented with $10 \mathrm{~g}$ daily of hydrolysed collagen, which was administered orally during 6 months, at home under real conditions of use, and (ii) without hydrolysed collagen supplementation.

The supplements based on collagen peptides (10 g) (Peptan $\AA$, Fascia Biolab, Brazil) were enriched with vitamins C (45 mg), E (10 mg) and biotin (30 mcg) (the last three doses were $100 \%$ of the recommended daily intake).

Prior to treatment and at follow-up visits, each patient underwent a clinical examination with a physician to assess overall health status. The inclusion criteria were: men and women between 45 and 65 years old, classified as grades II and III of ageing on the Glogau ladder, considered healthy after clinical examination by the physician, and who did not use any type of dermatological or aesthetic treatment in face topically, such as retinoic acid or hydroxy acids, and chemical peels in the last month. They also could not have had injections of poly-lactic acid or hyaluronic acid in the last 18 months and botulinum toxin type $\mathrm{A}$ in the last 12 months. Exclusion criteria were: volunteers not considered healthy after clinical examination by the physician; pregnant women; volunteers with known allergy/intolerance to collagen or some component of the supplement, or anaesthetic (lidocaine); volunteers who were not willing to adhere to the use 
of the supplement for the study period (6 months); volunteers using antiplatelet agents or continuoususe anticoagulants, which could interfere with postprocedure healing; volunteers with acquired or acquired immunodeficiencies; or other condition that the physician judged incapacitating for participation in the project.

The microneedling was performed in a hospital environment by a dermatologist. Topical anaesthetic lidocaine $4 \%$ was applied to the surface of the skin; after 30 minutes, the skin was sanitised with $70 \%$ alcohol, and the anaesthetic block of the supraorbital, supratrochlear, infraorbital and mental nerves was performed using 2\% lidocaine. A derma roller (DrRollerMTS Roller, MiRoll, Korea) of 1.5-mm needle length was used in each session. Each region was punctured eight times in different directions (vertical, up and down, horizontal, right and left and both diagonal senses) to generate uniform petechiae on all faces [16] to stimulate epidermal growth factors. At the end of the procedure, the skin was cleaned with sterile $0.9 \%$ physiological solution, and solid petroleum jelly was applied. For post-procedure care, we provided cleanser gel for use in the first 48 hours, and orientation for the patient to use sunscreen (SPF 30 and UVAPF 10) after 24 hours of the procedure and throughout the study.

The volunteers were evaluated at baseline, when the first microneedle session was performed, at $\mathrm{t} 1=30$ days, when the second session was performed and questionnaire was administered, at $\mathrm{t} 2=60$ days and at $\mathrm{t} 3=180$ days. Photographic records of the face of the volunteers were made in all time points, using a digital multispectral skin analysis system (Visia®, Canfield Imaging System, United Stated of America) by a single operator. The photographs were taken in frontal incidence, $45^{\circ}$ to the right and $45^{\circ}$ to the left. To evaluate rejuvenation, we used: (i) dermatological parameters: wrinkle depth and skin texture using the non-invasive multispectral skin analysis above mentioned; and (ii) determination of self-perceived efficacy using a questionnaire adapted from Ferreira et al. (2018) [17] - both at times $\mathrm{t} 1$ and $\mathrm{t} 3$. The skin evaluation, the photographic registration of the face and the questionnairesapplied to each participant were procedures performed always by the same researcher. The respect, confidentiality and confidentiality of volunteer information were ensured.
The questionnaire applied regarding the perception of the volunteer on improvement of the parameters listed followed a graduation scale of 1 to 10 , in which 1 was not observed improvement and 10 , a significant improvement. When the volunteer did not consider any characteristic before or after the intervention, they indicated that it does not apply. The results were grouped according to the classification proposed by Costa et al. (2015): score equal to 1: there was no improvement; between 2 and 4: little improvement; 5-7: moderate improvement and 8-10: significant improvement [18] .

The study was approved by the Committee of Ethics in Research with Human Beings of the Federal University of Juiz de Fora under protocol number 2,476,954. All procedures involved in this study are in accordance with the Declaration of Helsinki of 1975, updated in 2013. Informed consent was obtained from all participants included in the study.

For descriptive statistical analysis of the variables of multispectral analysis, all results were expressed as mean \pm standard deviation (SD). Statistical comparisons were made using the Student t-test, oneway analysis of variance (ANOVA), using the software Sisvar 5.6 (UFLA, 1996). A unit of measurement "classification" generated by Visia ${ }^{\circledR}$ was used. The scores of the two hemifaces were added to the right and left and measurements were taken each time between times 1 and 0,2 and 0 and 3 and 0 , which were as units compared using ANOVA. The analysis of the variables originated from the self-perception questionnaire, the descriptive examination was carried out in the form of a series of performance tests that promoted improved quality of life, significant improvement, moderate improvement and significant improvement. The quantitative analysis of the assigned scores from 10 to 10 was included in the delta of each individual's notes at times 180 and 30 days when they were compared using ANOVA.

\section{RESULTS}

The sample consisted of 30 volunteers: 14 women and 1 man in each group. There was a loss of follow-up in group 1, for reasons not related to the study. The mean age of the volunteers was $54 \pm 6.3$ years in group 1 (n $=14)$ and $55.5 \pm 5.36$ years in group $2(n=15)$.

In the classification of the patients'sphototype, phototype III was predominant: $35.71 \%$ in group 1 and $46.67 \%$ in group 2. 
Microneedling and Oral Replacement of Collagen as Strategies for Skin Rejuvenation

Using the classification of ageing according to the Glogau scale, four participants in group 1 were grade II and ten grade III; in group 2, six volunteers were grade II and nine grade III.

Both groups were considered similar in gender, age, phototype and degree of cutaneous aging. Smoking degree was also similar between groups, both contained one smoker and the rest were non-smokers. Smoking accelerates the process of extrinsic aging. It is responsible for premature aging, contributing to the appearance of facial wrinkles [19]. However, because of low prevalence of smoking volunteers, there was no impact on data analysis. Table 1 summarises the demographic characteristics of the volunteers in this study.

Table 1. Demographic characteristics of study participants.

\begin{tabular}{|c|c|c|c|}
\hline & $\begin{array}{c}\text { Group 1: Microneedling } \\
\text { + colagen (\%) }\end{array}$ & $\begin{array}{c}\text { Group 2: Microneedling } \\
(\%)\end{array}$ & Total (\%) \\
\hline \multicolumn{4}{|l|}{ Gener } \\
\hline Feminine & $13(92.86)$ & $14(93.33)$ & $27 \quad(93.10)$ \\
\hline Masculine & $1 \quad(7.14)$ & $1 \quad(6.67)$ & $2 \quad(6.90)$ \\
\hline \multicolumn{4}{|c|}{ Fitzpatrick phototype } \\
\hline II & $\begin{array}{ll}4 \quad(28.57) \\
\end{array}$ & $3(20.00)$ & $\begin{array}{ll}77 & (24.13) \\
\end{array}$ \\
\hline III & $5 \quad(35.71)$ & 7 (46.67) & $12 \quad(41.38)$ \\
\hline IV & $4 \quad(28.57)$ & $4 \quad(26.67)$ & $\begin{array}{ll}8 & (27.59) \\
\end{array}$ \\
\hline $\mathrm{V}$ & $1 \quad(7.14)$ & $1 \quad(6.67)$ & $2 \quad(6.90)$ \\
\hline Age (average \pm SD) & $54 \pm 6.3$ & $55.5 \pm 5.63$ & \\
\hline \multicolumn{4}{|l|}{ Glogau Scale } \\
\hline II & $4(28.57)$ & $6(40)$ & 10 \\
\hline III & $10(71.43)$ & $9(60)$ & 19 \\
\hline \multicolumn{4}{|l|}{ Tabagism } \\
\hline Yes & $1(7.14)$ & $1(6.67)$ & $2(6.90)$ \\
\hline No & $13(92.86)$ & $14(93.33)$ & $27(93.10)$ \\
\hline
\end{tabular}

In group 1, 78.5\% of the volunteers reported a significant improvement in the overall appearance of the end-to-end time, and 50\% in group 2.

For perilabial wrinkles, the number of participants in group 1 who attributed significant improvement increased from $28.5 \%(\mathrm{t} 1)$ to $78.5 \%(\mathrm{t} 3)$. In group 2 , the increase was from $50 \%(\mathrm{t} 1)$ to $61.35 \%(\mathrm{t} 3)$ (p $<0.05$ ).

For the frontal wrinkles variable, $64.2 \%$ of volunteers in group 1 and $50 \%$ in group 2 reported a significant improvement at the end of the study. For periocular wrinkles, $57.1 \%$ of volunteers in group 1 and $61.5 \%$ in group 2 attributed the greatest improvement after 180 days.

On signs of aging, significant improvement was observed in $78.5 \%$ of volunteers in group 1 at the final time, and $42.8 \%$ in group 2 . In relation to lushness, $64.2 \%$ in group 1 reported significant improvement after 180 days and $57.1 \%$ in group 2 . When assessing homogeneity of skin, $78.5 \%$ in group 1 classified as significant improvement at the end of the study, and $57.1 \%$ in group 2. For the number of darkened areas, $70 \%$ in group 1 and $40 \%$ in group 2 attributed significant improvement in the final time; for the intensity of these darkened areas, 50\% in group 1 and $44.4 \%$ in group 2 reported significant improvement. The significant improvement in skin smoothness was attributed in $71.4 \%$ of volunteers in group 1 after 180 days, and in $64.2 \%$ of group 2 .

The percentage of volunteers who reported a significant improvement in the bleaching effect and pore dilation after final evaluation was the same in both groups, $69.2 \%$ and $66.6 \%$, respectively.

The only variables that the significant improvement was related in higher percentage in group 2 when compared to group 1, at the end of the evaluation, were: uniformity of imperfections $64.2 \%$ in group 1 vs. $69.2 \%$ in group 2; oiliness $50 \%$ (group 1) vs. $66.6 \%$ (group 2) and scars $33.3 \%$ in group 1 vs. $62.5 \%$ group 2 .

The results of the self-perception evaluation (Table 2) suggest that the associated strategies (microneedling associated with oral collagen supplementation) offer a higher degree of satisfaction for most aspects evaluated: general appearance, periorbital and frontal wrinkles, ageing, lustre, softness, homogeneity, quantity and intensity of darkened areas and 
Microneedling and Oral Replacement of Collagen as Strategies for Skin Rejuvenation

whitening effect. However, statistical significance was found only for perioral wrinkles. Costa et al. (2015) also used self-evaluation in a study that evaluated oral supplementation of collagen for rejuvenation, and observed superiority in the improvement of skin quality in the supplemented group[18], as well as the present study. In another study that also aimed to evaluate the effectiveness of oral supplementation of hydrolysed collagen (HC) in skin rejuvenation, parameters such as high resolution photography and probes (able to evaluate skin hydration and elasticity) to measure skin aspects after 8 weeks of supplementation were used, and the authors concluded that such replacement be considered an effective strategy for rejuvenation[15].

A low percentage of volunteers in both groups (below $15 \%$ ) considered graduation of improvement, that is, maintenance of the status prior to the proposed treatment, as low. This finding corroborates the finding that both the microneedle and oral replacement of collagen techniques generate high patient satisfaction.

Table 2. Evaluation of the self-perception parameters in each treatment group at the initial ( $t 1)$ and final ( $t 3$ ) times, expressed as a percentage of participants.

\begin{tabular}{|c|c|c|c|c|c|c|c|c|c|}
\hline \multirow[t]{2}{*}{ Parameter } & \multirow[t]{2}{*}{ Group } & \multicolumn{2}{|c|}{ Maintenance } & \multicolumn{2}{|c|}{$\begin{array}{c}\text { Little } \\
\text { improvement }\end{array}$} & \multicolumn{2}{|c|}{$\begin{array}{c}\text { Moderate } \\
\text { improvement }\end{array}$} & \multicolumn{2}{|c|}{$\begin{array}{c}\text { Significative } \\
\text { improvement }\end{array}$} \\
\hline & & $\mathrm{t} 1$ & $\mathrm{t} 3$ & $\mathrm{t} 1$ & $\mathrm{t} 3$ & $\mathrm{t} 1$ & $\mathrm{t} 3$ & $\mathrm{t} 1$ & $\mathrm{t} 3$ \\
\hline \multirow[t]{2}{*}{ Appearance } & G1 & 7.14 & 7.14 & 7.14 & 7.14 & 21.4 & 7.14 & 64.2 & 78.5 \\
\hline & G2 & 0 & 7.14 & 6.6 & 0 & 33.3 & 42.8 & 60 & 50 \\
\hline \multirow[t]{2}{*}{ Wrinkles - lips } & G1 & 14.2 & 14.2 & 0 & 0 & 57.1 & 7.14 & 28.5 & 78.5 \\
\hline & $\mathrm{G} 2$ & 0 & 7.69 & 21.4 & 15.38 & 28.5 & 15.38 & 50 & 61.53 \\
\hline \multirow[t]{2}{*}{ Wrinkles - forehead } & G1 & 7.14 & 7.14 & 7.14 & 7.14 & 42.8 & 21.4 & 42.8 & 64.2 \\
\hline & $\mathrm{G} 2$ & 7.14 & 7.14 & 0 & 0 & 35.7 & 42.8 & 57.1 & 50 \\
\hline \multirow[t]{2}{*}{ Wrinkles - eyes } & G1 & 14.2 & 7.14 & 0 & 7.14 & 42.8 & 28.5 & 42.8 & 57.1 \\
\hline & $\mathrm{G} 2$ & 6.6 & 0 & 6.6 & 7.69 & 33.3 & 30.7 & 53.3 & 61.5 \\
\hline \multirow[t]{2}{*}{ Aging signals } & G1 & 7.14 & 7.14 & 7.14 & 7.14 & 28.5 & 7.14 & 57.1 & 78.5 \\
\hline & G2 & 6.6 & 7.14 & 6.6 & 7.14 & 33.3 & 42.8 & 53.3 & 42.8 \\
\hline \multirow[t]{2}{*}{ Lushness } & G1 & 7.14 & 0 & 0 & 7.14 & 14.7 & 28.5 & 78.5 & 64.2 \\
\hline & G2 & 6.6 & 7.14 & 0 & 0 & 26.6 & 35.7 & 66.6 & 57.1 \\
\hline \multirow[t]{2}{*}{ Homogeneity } & G1 & 0 & 0 & 0 & 7.14 & 28.5 & 14.7 & 64.2 & 78.5 \\
\hline & $\mathrm{G} 2$ & 0 & 7.14 & 14.7 & 7.14 & 14.7 & 28.5 & 57.1 & 57.1 \\
\hline \multirow[t]{2}{*}{ Quantity of darken areas } & G1 & 14.2 & 20 & 14.2 & 0 & 0 & 10 & 71.4 & 70 \\
\hline & $\mathrm{G} 2$ & 20 & 0 & 0 & 10 & 30 & 50 & 50 & 40 \\
\hline \multirow[t]{2}{*}{ Intensity of darken areas } & G1 & 12.5 & 10 & 12.5 & 10 & 12.5 & 30 & 62.5 & 50 \\
\hline & $\mathrm{G} 2$ & 20 & 11.1 & 10 & 11.1 & 30 & 33.3 & 50 & 44.4 \\
\hline \multirow[t]{2}{*}{ Softness } & G1 & 7.14 & 0 & 0 & 7.14 & 14.7 & 21.4 & 78.5 & 71.4 \\
\hline & G2 & 0 & 7.14 & 7.14 & 0 & 21.4 & 28.5 & 71.4 & 64.2 \\
\hline \multirow[t]{2}{*}{ Whithening } & G1 & 14.7 & 0 & 14.7 & 7.69 & 7.14 & 23.07 & 64.2 & 69.2 \\
\hline & $\mathrm{G} 2$ & 7.69 & 7.69 & 15.38 & 7.69 & 15.38 & 15.38 & 61.5 & 69.2 \\
\hline \multirow[t]{2}{*}{ Imperfections uniformity } & G1 & 9.09 & 7.14 & 0 & 0 & 36.3 & 28.5 & 54.5 & 64.2 \\
\hline & $\mathrm{G} 2$ & 7.14 & 7.69 & 14.7 & 7.69 & 28.5 & 15.38 & 50 & 69.2 \\
\hline \multirow[t]{2}{*}{ Pore dilatation } & G1 & 30 & 0 & 0 & 8.3 & 30 & 25 & 40 & 66.6 \\
\hline & G2 & 0 & 0 & 9.09 & 8.3 & 27.2 & 25 & 63.6 & 66.6 \\
\hline \multirow[t]{2}{*}{ Oiliness } & G1 & 11.1 & 8.3 & 11.1 & 8.3 & 44.4 & 33.3 & 33.3 & 50 \\
\hline & G2 & 8.3 & 9.09 & 8.3 & 0 & 8.3 & 18.1 & 75 & 66.6 \\
\hline \multirow[t]{2}{*}{ Scars } & G1 & 0 & 33.3 & 0 & 0 & 50 & $\begin{array}{l}33.3 \\
\end{array}$ & 50 & $\begin{array}{l}33.3 \\
\end{array}$ \\
\hline & G2 & 25 & 0 & 25 & 12.5 & 25 & 25 & 25 & 62.5 \\
\hline
\end{tabular}

t1: 30 days, t3: 180 days. G1: group 1, G2: group 2. 
Microneedling and Oral Replacement of Collagen as Strategies for Skin Rejuvenation

Most of the adverse effects were mild pain during the procedure, sensation of redness and burning afterwards, and transient erythema, with a maximum duration of 48 hours and spontaneous resolution, requiring no intervention. The incidence of adverse effects was similar in both groups, suggesting that they are secondary to the microneedling. There was only one case of unilateral infrapalpebral ecchymosis, which we attributed to a probable puncture injury when performing the infraorbital anaesthetic block, but which regressed spontaneously, without complications.

At the beginning of the study, the groups were homogeneous in the wrinkle variable. However, for the texture variable, they were different at the beginning

Table 3. Multispectral analyses of face (wrinkles and texture) of volunteers submitted to treatment strategies over 180 days.

\begin{tabular}{|l|c|c|c|c|c|c|c|c|}
\hline & \multicolumn{4}{|c|}{$\begin{array}{c}\text { Microneedling } \\
\text { + colagen }\end{array}$} & \multicolumn{5}{c|}{ Microneedling } \\
\cline { 2 - 10 } & t0 & t1 & t2 & t3 & t0 & t1 & t2 & t3 \\
\hline Wrinkles & & & & & & & & \\
\hline Average & 56.43 & 48.78 & 50.68 & 49.54 & 50.30 & 53.19 & 52.43 & 54.69 \\
\hline Standard deviation & 12.05 & 11.36 & 12.29 & 13.67 & 11.44 & 16.83 & 16.51 & 11.25 \\
\hline Texture & & & & & & & & \\
\hline Average & 43.03 & 40.51 & 39.83 & 40.42 & 29.51 & 31.46 & 31.53 & 30.13 \\
\hline Standard deviation & 17.62 & 16.86 & 14.36 & 19.03 & 14.66 & 15.21 & 16.03 & 16.47 \\
\hline
\end{tabular}

Table 4 shows the differences in the scores of times 30 , 60 and 180 days in relation to the baseline. When the deltas between the two groups were compared, it was observed that only delta 3 (t180 - t0) of the wrinkles'

variable presented a statistically significant difference between the groups, and group 1 (microneedling associated with oral collagen supplementation) was higher than group 2 (isolated microneedling).

Table 4. Comparison of the deltas between the groups for the multispectral analyses variables.

\begin{tabular}{|l|c|c|c|c|c|c|c|c|c|}
\hline & G1 & G2 & & G1 & G2 & & G1 & G2 & \\
\cline { 2 - 10 } & \multicolumn{2}{|c|}{ Delta 1 } & p & \multicolumn{2}{|c|}{ Delta 2 } & p & \multicolumn{2}{|c|}{ Delta 3 } & p \\
\hline Wrinkles & -7.65 & 2.89 & $0.0355^{*}$ & -5.75 & 2.13 & 0.1697 & -6.89 & 4.39 & $0.0320^{*}$ \\
\hline Texture & -2.51 & 1.95 & 0.1653 & -3.19 & 2.03 & 0.1473 & -2.61 & 0.63 & 0.4463 \\
\hline
\end{tabular}

Delta 1: sum time 1 minus the sum time 0; Delta 2: sum time 2 minus the sum time 0; Delta 3: sum time 3 minus the sum time $0 .{ }^{*} \mathrm{p}<0.05$. G1: group 1, G2: group 2.

The wrinkles and texture variables improved in the group treated with microneedling and oral replacement of collagen, but no improvement was seen in the group treated which microneedling only. However, texture improvement was not statistically significant $(p=0.44)$. We can attribute this result to the

difference found between baseline groups in relation to the texture variable, possibly if they were similar at the beginning of the study, the difference found at t3 would be statistically significant. Before baseline, mean wrinkle count in group 1 was 56.43, and 49.54 at $\mathrm{t} 3$, showing a $12 \%$ improvement at the end of the study ( $p=0.032)$. In group 2 , the initial count was of 50.30 and final of 54.69, in this occurred a worsening of $9 \%$, without statistical significance. For texture, the mean initial count in group 1 was 43.03 and the final, 
40.42 , an improvement of $6 \%$. In group 2 , the initial count was 29.51 and at the end, 30.13, a worsening of $2 \%$, in both groups with no statistical significance.

\section{Discussion}

Microneedling is a minimally invasive technique that can be performed in the outpatient setting and has evidence of efficacy for treatment of skin aging, acne scarring, androgenetic alopecia, melasma, vitiligo, actinic keratosis, among others [20]. There are already reports of the association of the technique with chemical peeling [21] and drug delivery of other substances (platelet-rich plasma, tranexamic acid, bleomycin) $[20,22]$, but we did not find the association of the technique with the use of oral collagen. Our study proposed this unprecedented approach: percutaneous induction of collagen by microneedles and oral replacement of collagen peptides.

Significant improvement of wrinkles was observed in the group that supplemented collagen than in the group that received only the microneedle. Texture improved in the supplemented group, but without statistical significance. These findings are in line with other studies. Proksch et al. (2014) conducted a double-blind, randomised, placebo-controlled study involving 69 women to evaluate the effects of oral HC supplementation. A statistically significant improvement in skin elasticity - a condition related to skin ageing - was observed in the treated group, being even more significant in the subgroup older than 50 years [14].

El-domiaty et al. (2015) carried out six microneedling sessions in 10 patients, with clinical improvement evident by anatomopathology [23]. The same authors, in 2018, recruited 24 volunteers to evaluate microneedling isolated and associated with other modalities for treatment of aging, and observed clinical and histopathological improvement in all modalities, the superior improvement observed when combined techniques were used [21].

On the efficacy of collagen use, Costa et al. (2015) evaluated 47 men after 180 days of collagencontaining compound supplementation and observed improvement of dermal density by ultrasound, increase in the percentage of collagen and elastic fibres through biopsies and improvement of the general aspects of the skin through multispectral analysis [18], data that are in line with the findings of the present study. Campos et al. (2019) conducted a study with 60 volunteers and observed improvement of viscoelasticity and cutaneous echogenicity after 90 days of HC supplementation, as well as reduction of wrinkles and pores, suggesting that HC oral replacement can improve aspects of skin photoaging, corroborating the benefit of using collagen as a rejuvenating strategy [11].

Lee et al. (2014) performed a split-face study with 25 women, one hemiface received microneedling in isolation (needle length $0.25 \mathrm{~mm}$ ) and the other microneedling and drug-delivery of stem-derived growth factor. After 12 weeks of study, only wrinkles improved in the hemiface treated with growth factor [7]. According to Lima (2013), it is possible to attribute the lack of improvement on the side treated with microneedles only to the length of needles chosen, since the size of $0.25 \mathrm{~mm}$ is not capable of promoting sufficient injury capable of stimulating the production of collagen [16].

The worsening observed in this study, in the group that received the microneedling alone, is not observed in the literature. Aust et al. (2008) performed a retrospective study involving 480 patients, who were submitted to microneedling. Out of these, 350 were performed with the aim of improving facial wrinkles. On an analogue scale of self-perception, this index improved on average from 4.5 to 8.5 ( $p<0.005$ ) [24]. In addition, biopsies were performed in part of the volunteers, which showed an increase in the production of collagen and elastin.

At the end of the 180 days of follow-up, no significant adverse effects were observed in the 29 subjects in this study. All participants had immediate erythema in the immediate post-procedure with petechial points, and this was the desired end point. As symptoms, they reported local heat, burning sensation, all expected and resolved in the first 12 hours. The erythema remained for a maximum of 48 hours. In the literature, some adverse events such as reactivation of herpes simplex have already been reported [25], but most only observe transient events - discomfort, erythema and edema [20], as well as the present study. Microneedling is considered a safe procedure even in higher phototypes (IV-VI), as observed in a systematic review conducted by Cohen et al. (2016), which included evaluating multiple therapeutic indications of microneedling with low indices of adverse effects in more phototypes high [9]. This is 
considered an advantage over conventional ablative procedures, which have higher rates of dysrhythmic complications. This can be attributed to the minimal damage generated to the epidermis and to the nonproduction of heat.

We consider as limitations of this clinical trial the absence of anatomopathological or confocal microscopy, methods of evaluation that objectively evidence the increase of collagen production and thickening of the dermis, respectively.

\section{CONCLUSION}

Microneedling associated with oral collagen replacement is an innovative resource used in the treatment of ageing by generating an improvement in the distribution of collagen fibres, influencing the reduction of wrinkles and improving the general appearance of the skin, in addition to promoting a high degree of patient satisfaction.

\section{Potential Conflicts of Interest}

The authors declare that they have no conflicts of interest to disclose.

\section{REFERENCES}

[1] Alexis AF, Obioha JO. Ethnicity and Aging Skin. J Drugs Dermatol. 2017 Jun 1;16(6):s77-s80. [PMID: 29028856].

[2] Bolognia JL, Jorizzo JL, Schaffer JV. Dermatologia. Rio de Janeiro. Elsevier, 2015.

[3] Dayan SH, Bacos JT, Ho TT, et al. Topical skin therapies in subjects undergoing full facial rejuvenation. J Cosmet Dermatol. 2019 Apr 29. [PMID: 31033162].

[4] Lee JC, Daniels MA, Roth MZ. Mesotherapy, Microneedling, and Chemical Peels. Clin Plast Surg. 2016 Jul;43(3):583-95. [PMID: 27363773].

[5] Elghblawi, E. Medical micro-needling. TricholCosmetol Open J. 2017; 1(1): 21-24.

[6] Singh A, Yadav S. Microneedling: Advances and widening horizons. Indian Dermatol Online J. 2016 Jul-Aug;7(4):244-54. [PMID: 27559496].

[7] Lee HJ, Lee EG, Kang S, et al. Efficacy of Microneedling Plus Human Stem Cell Conditioned Medium for Skin Rejuvenation: A Randomized, Controlled, Blinded Split-Face Study. Ann Dermatol. 2014;26(5):584-591. [PMID: 25324650].
[8] McCrudden MT, McAlister E, Courtenay AJ, et al. Microneedle applications in improving skin appearance.ExpDermatol.2015Aug;24(8):561-6. [PMID: 25865925].

[9] Cohen BE, Elbuluk N. Microneedling in skin of color: A review of uses and efficacy. J Am Acad Dermatol. 2016 Feb;74(2):348-55. [PMID: 26549251].

[10] Hartmann D, Ruzicka T, GauglitzGG. Complications associated with cutaneous aesthetic procedures. J Dtsch Dermatol Ges. 2015 Aug;13(8):778-86. [PMID: 26177157].

[11] Maia Campos PMBG, Melo MO, Siqueira César FC. Topical application and oral supplementation of peptides in the improvement of skin viscoelasticity and density. J Cosmet Dermatol. 2019 Mar 4. [PMID: 30834689].

[12] Yazaki M, Ito Y, Yamada M, et al. Oral Ingestion of Collagen Hydrolysate Leads to the Transportation of Highly Concentrated Gly-ProHyp and Its Hydrolyzed Form of Pro-Hyp into the Bloodstream and Skin. J Agric Food Chem. 2017 Mar 22;65(11):2315-2322. [PMID: 28244315].

[13] Matsuda N, Koyama Y, Hosaka Y, et al. Effects of ingestion of collagen peptide on collagen fibrils and glycosaminoglycans in the dermis. J Nutr Sci Vitaminol (Tokyo) 2006; 52: 211-215. [PMID: 16967766].

[14] Proksch E, Segger D, Degwert J, et al. Oral supplementation of specific collagen peptides has beneficial effects on human skin physiology: a double-blind, placebo-controlled study. Skin Pharmacol Physiol. 2014;27(1):47-55. [PMID: 23949208].

[15] Inoue N, Sugihara F, Wang X. Ingestion of bioactive collagen hydrolysates enhance facial skin moisture and elasticity and reduce facial ageing signs in a randomised double-blind placebocontrolled clinical study. J Sci Food Agric. 2016 Sep;96(12):4077-81. [PMID: 26840887].

[16] Lima EVA, Lima MA, Takano D. Microneedling experimental study and classification of the resulting injury. Surg Cosmet Dermatol 2013;5(2):1104.

[17] Ferreira AO, Freire ES, Polonini HC, et al. AntiAging Effects of Monomethylsilanetriol and 
Microneedling and Oral Replacement of Collagen as Strategies for Skin Rejuvenation

Maltodextrin-Stabilized Orthosilicic Acid on

Nails, Skin and Hair. Cosmetics 2018, 5, 41.

[18] Costa A, Pegas Pereira ES, Assumpção EC, et al. Assessment of clinical effects and safety of an oral supplement based on marine protein, vitamin $\mathrm{C}$, grape seed extract, zinc, and tomato extract in the improvement of visible signs of skin aging in men. Clin CosmetInvestig Dermatol. 2015 Jun 29;8:319-28. [PMID: 26170708].

[19] Amer M, Farag F, Amer A, ElKot R, Mahmoud $R$. Dermapen in the treatment of wrinkles in cigarette smokers and skin aging effectively. J Cosmet Dermatol. 2018 Dec;17(6):1200-1204. [PMID: 30549208].

[20] Iriarte C, Awosika O, Rengifo-Pardo M, Ehrlich A. Review of applications of microneedling in dermatology. Clin CosmetInvestig Dermatol. 2017 Aug 8;10:289-298. [PMID: 28848356].

[21] El-Domyati M, Abdel-Wahab H, Hossam A. Combining microneedling with other minimally invasive procedures for facial rejuvenation: a split-face comparative study. Int J Dermatol. 2018 Nov;57(11):1324-1334. [PMID: 30105816].

[22] Badran KW, Nabili V. Lasers, Microneedling, and Platelet-Rich Plasma for Skin Rejuvenation and Repair. Facial Plast Surg Clin North Am. 2018 Nov;26(4):455-468. [PMID: 30213427].

[23] El-Domyati M, Barakat M, Awad S, et al. Multiple microneedling sessions for minimally invasive facial rejuvenation: an objective assessment. Int J Dermatol 2015;54:1361-9. [PMID: 26096653].

[24] Aust MC, Fernandes D, Kolokythas P, Kaplan HM, Vogt PM. Percutaneous collagen induction therapy: an alternative treatment for scars, wrinkles, and skin laxity. PlastReconstr Surg. 2008 Apr;121(4):1421-9. [PMID: 18349665].

[25] Ablon G. Safety and Effectiveness of an Automated Microneedling Device in Improving the Signs of Aging Skin. J Clin Aesthet Dermatol. 2018 Aug;11(8):29-34. [PMID: 30214664].

Citation: Érika Santos Freire, Maria Cristina Vieira de Andrade, et al. Microneedling and Oral Replacement of Collagen as Strategies for Skin Rejuvenation. Archives of Dermatology and Skin Care. 2019; 2(2): 07-15.

Copyright: (C) 2019 Érika Santos Freire, Maria Cristina Vieira de Andrade, et al. This is an open access article distributed under the Creative Commons Attribution License, which permits unrestricted use, distribution, and reproduction in any medium, provided the original work is properly cited. 